\title{
STUDY OF FUTURE CLIMATIC VARIATIONS OF A TELECONNECTION PATTERN AFFECTING EASTERN MEDITERRANEAN
}

\author{
M. HATZAKI ${ }^{1, *}$ \\ H.A. FLOCAS ${ }^{1}$ \\ P. MAHERAS ${ }^{2}$ \\ D.N. ASIMAKOPOULOS ${ }^{1}$ \\ C. GIANNAKOPOULOS ${ }^{3}$
}

\author{
${ }^{1}$ Department of Applied Physics, Faculty of Physics \\ University of Athens, Building PHYS-5, \\ University Campus, 15784 Athens, Greece \\ ${ }^{2}$ Department of Meteorology and Climatology \\ University of Thessaloniki, 54006 Thessaloniki, Greece \\ ${ }^{3}$ Institute for Environmental Research and Sustainable \\ Development, National Observatory of Athens \\ V.Pavlou \& I.Metaxa str, P. Penteli, 15236 Athens, Greece \\ *to whom all correspondence should be addressed: \\ e-mail: marhat@phys.uoa.gr
}

Received: 23/03/06

Accepted: 31/05/06

\begin{abstract}
A teleconnection pattern has been identified between Eastern Mediterranean and Northwestern Europe in the geopotential fields of the upper troposphere (hereafter will be referred to as EMP) during winter and it seems to play significant role in the large-scale atmospheric circulation over Mediterranean region with distinctive temporal and spatial characteristics. Since teleconnections are significant components of the natural climatic variability, any future climatic changes are expected to influence their structure and intensity and subsequently their implications on the regional climate.
\end{abstract}

Taking into account these findings, the aim of this study is to investigate the existence of EMP and its potential spatial variations in the future, in connection with the IPCC Emission Scenarios of greenhouse gases. For this purpose, gridded daily data of geopotential height at $500 \mathrm{hPa}$ have been used. For the present climate, the datasets derive from NCEP/NCAR archive and cover the period 1958 to 2003 on $2.5^{\circ} \times 2.5^{\circ}$ latitude by longitude grid. For the future, the datasets derive from HadAM3P model for the period 2070-2100, on the basis of two different IPCC scenarios. Two different approaches were employed on a seasonal basis in order to identify the centres of action for this pattern: Rotated Principal Component Analysis and Correlation analysis.

First, the validation of the model results (control run) against the gridded data of NCEP/NCAR for the present period 1960-1990 demonstrated that the two datasets agree quite well. Then, it was found that the EMP exists in the future (2070-2100) under different scenarios of greenhouse gases emissions and subsequent global warming but not in its present form. For the scenario that predicts global temperature increase by $2.3^{\circ} \mathrm{C}$, the pattern forms with a northeastward shift of the two poles relative to location in the present climate. If the global temperature increase is higher (of $3.3^{\circ} \mathrm{C}$ ), the whole EMP is shifted to the southeast by almost $10^{\circ}$, as compared to its present form. These results are collaborated by both approaches employed.

KEYWORDS: teleconnection patterns, climatic changes, Eastern Mediterranean, principal component analysis, correlation analysis 


\section{INTRODUCTION}

The term "teleconnection pattern" refers to the statistically significant negative correlation of recurring and persistent circulation anomalies between two or more geographical areas that could be adjacent or at greater distances. Teleconnection patterns appear as preferred modes of low-frequency (or long time scale) natural variability of the atmospheric circulation with geographically fixed centres of action (poles).

Two approaches have been used in relevant studies to define low-frequency circulation patterns: a) correlation analysis where the two (or more) poles of the pattern are characterized by the strongest negative correlations in the domain [1], [2], [3], [4], [5]. However, this method requires considerable time of both the computer and researcher while it is not straightforward to define the most representative set of centers within the spatial coverage of the pattern or its temporal evolution and b) rotated principal component analysis (RPCA), where the eigenvectors of the correlation matrix are individually scaled according to their contribution to the total data variance and then are rotated under certain constraints to obtain the most detailed and robust teleconnection counterparts [6], [7], [8], [9]. While RPCA offers advantage of its ability to reduce the original dataset into the fewest number of significant independent components and computational convenience compared to the previous method, it is characterized by certain constraints being associated with the selection of the principal components (PCs) and their physical interpretation.

Climate dynamics research has demonstrated the existence of several teleconnection patterns over the European region such as North Atlantic Oscillation (NAO) in the lower troposphere between Iceland and Azores [1], [8], [10], Eastern Atlantic pattern, as the upper air manifestation of NAO [1], [4], Southern Europe-North Atlantic pattern (SENA) at $700 \mathrm{hPa}$ [11], Eastern Atlantic-West Russia Pattern (EAWR) at $700 \mathrm{hPa}$ [12] and North Sea-Caspian pattern at $500 \mathrm{hPa}$ [5]. Furthermore, Conte et al. [13] suggested the existence of a teleconnection pattern in the annual geopotential height fields at $500 \mathrm{hPa}$ between the two extremes of the Mediterranean basin that was defined as Mediterranean Oscillation. They defined the Mediterranean Oscillation index (MOI) as the standardized geopotential height difference between Alger and Cairo. Recent studies demonstrated that this oscillation is reflected in the time series of temperature and rainfall between Western and Eastern Mediterranean [14], [15], [16], and [17].

In an attempt to further investigate the Mediterranean Oscillation, a new teleconnection pattern was found in the geopotential field between Eastern Mediterranean and Northwestern Europe (hereafter will be referred to as EMP) at 300 and $500 \mathrm{hPa}$ in winter [18], [19]. This pattern seems very weak in spring and summer, weakens at lower levels and does not exist at $1000 \mathrm{hPa}$. Furthermore, Hatzaki et al. [20] demonstrated that EMP is associated with an increase that was evident in the winter precipitation in Eastern Mediterranean region and a significant overall increase in the winter minimum temperature.

As significant component of the natural climatic variability, future climatic changes are expected to influence their structure and intensity and subsequently their implications on the regional climate [21], [22]. This issue appears as the subject of current climatological research with the aid of global circulation models (GCMs) and regional climatic models or statistical downscaling methods. The objective of this study is to explore the existence and the characteristics of the EMP in the future at the isobaric level of $500 \mathrm{hPa}$ in winter, using the results of a General Circulation Model (GCM) for two different IPCC Emission Scenarios of greenhouse gases, with the aid of both above mentioned approaches: correlation and principal component analysis.

\section{DATA - METHODOLOGY}

In this study gridded datasets of geopotential height at $500 \mathrm{hPa}$ were used on a daily basis for the European region, extending from $20^{\circ} \mathrm{W}$ to $50^{\circ} \mathrm{E}$ and $20^{\circ}$ to $50^{\circ} \mathrm{N}$. For the present climate, the datasets derive from NCEP/NCAR archive and cover the period 1958 to 2003 on $2.5^{\circ} \mathrm{x}$ $2.5^{\circ}$ latitude by longitude grid. For the future climate, modeled data derived from the General Circulation Model (GCM) HadAM3P [23] for the period 2070 to 2100 on a $2.5^{\circ} \times 2.5^{\circ}$ latitude by longitude grid, considering two different scenarios. The GCM data became available 
through the EU project STARDEX (Statistical and Regional Dynamical Downscaling of Extremes for European Regions).

The scenarios which were used belong to the A2 and B2 storylines and families, the A2a and $\mathrm{B} 2 \mathrm{a}$, respectively. In particular, the A2 storyline family describes a very heterogeneous world, presuming self-reliance and preservation of local identities. Fertility patterns across regions converge very slowly, which results in continuously increasing global population. Economic development is primarily regionally oriented. This scheme results in medium high emissions, with atmospheric $\mathrm{CO}_{2}$ concentrations reaching $715 \mathrm{ppm}$ and global temperatures expected to increase by around $3.3^{\circ} \mathrm{C}$ by the 2080s. The B2 storyline describes a world in which the emphasis is on local solutions to economic, social, and environmental sustainability. It describes a world with continuously increasing global population at a rate lower than A2, intermediate levels of economic development. While the scenario is also oriented toward environmental protection and social equity, it focuses on local and regional levels. The accompanying emissions scenario is medium low, with $\mathrm{CO}_{2}$ concentrations at 562ppm and global temperatures expected to increase by around $2.3^{\circ} \mathrm{C}$ [24].

The validation of the two datasets was performed for the period 1960-1990, which is the standard validation period in the climatic modeling studies, because it is not associated with important anthropogenic changes in the chemical composition of the atmosphere that mainly occurred during the last two decades. It should be noted that for the needs of a comparative study the examined area was selected on the basis of the scenario data availability while our analysis with the NCEP/NCAR refers to larger area, extending from $90^{\circ} \mathrm{W}$ to $90^{\circ} \mathrm{E}$ and $0^{\circ}$ to $90^{\circ} \mathrm{N}$.

The mean winter values for each time series were calculated. In this study, the standard definition of winter was followed. Following this definition, winters were extracted for each year using the December data of the previous year, resulting to reduce the datasets by one year.

Principal component analysis (PCA) is applied for the winter mean values of the three datasets. The first four principal components (PCs) are retained for all datasets that satisfy the empirical criterion of each component explaining more than the $10 \%$ of the total variance, trying to keep the PCs with physical interpretability [9]. These PCs share from 70 to $80 \%$ of the total variance. Finally, varimax method is used for the PCs' rotation [6] which maximizes the variance of the squared correlation coefficients between each rotated principal component and each of the original time series, thus increases the discrimination among the loadings and makes them easier to interpret [8]. Also, the rotated PCs are less dependent on the domain of the analysis and their spatial patterns more closely resemble observed anomaly fields [6].

Linear correlation coefficient was calculated between all grids in the whole examined region and one point correlation maps were constructed, in order to reveal any spatial changes of the pattern. The statistical significance was tested at the level of $a=0.05$. Then teleconnectivity maps were formulated, representing the poles of the pattern, as the points that appear maximum absolute value of negative correlation coefficient over the examined area [1].

\section{RESULTS}

Before proceeding to the correlation and principal component analysis for the future scenarios, the HadAM3P output (control run) of $500 \mathrm{hPa}$ geopotential heights was verified against the corresponding NCEP/NCAR values for the present period 1960-1990. The verification was performed on the basis of the biases of the mean winter values and the standard deviation ratios of the two datasets.

As can be seen in Figure 1, the HadAM3P values are higher compared to the NCEP value over the most part of European and Mediterranean region, with maximum biases (of $35 \mathrm{gpm}$ ) over western Mediterranean and Western Europe. Over Eastern Mediterranean, where the southern pole of the EMP is located, the biases are small, not exceeding the $15 \mathrm{gpm}$. On the contrary, over northeastern Atlantic - where the northern EMP pole is located - a strong gradient forms with biases ranging from 25 (model overestimation) to $-35 \mathrm{gpm}$ (model underestimation). From Figure 2 it becomes evident the HadAM3P values exhibit similar variability with the NCEP values over the whole examined area, except of north Africa where 
the model presents slightly lower variability. Especially, the regions of the two EMP poles are characterized by standard deviation ratio of 0.9-1. Furthermore, Tolika [25] demonstrated the sufficient adequacy of HadAM3P model to reproduce the principal component loadings of geopotential field at $500 \mathrm{hPa}$ over the examined area in all seasons, except for summer.

The correlation analysis verified the existence of strong negative correlation between northwestern Europe and Eastern Mediterranean for the future period 2070-2100. However, the two poles (as defined with the aid of the teleconnectivity maps) do not coincide with the corresponding ones identified in the present climate (Figure 3), but have changed by almost $10^{\circ}$ in different directions, depending on the considered scenario.

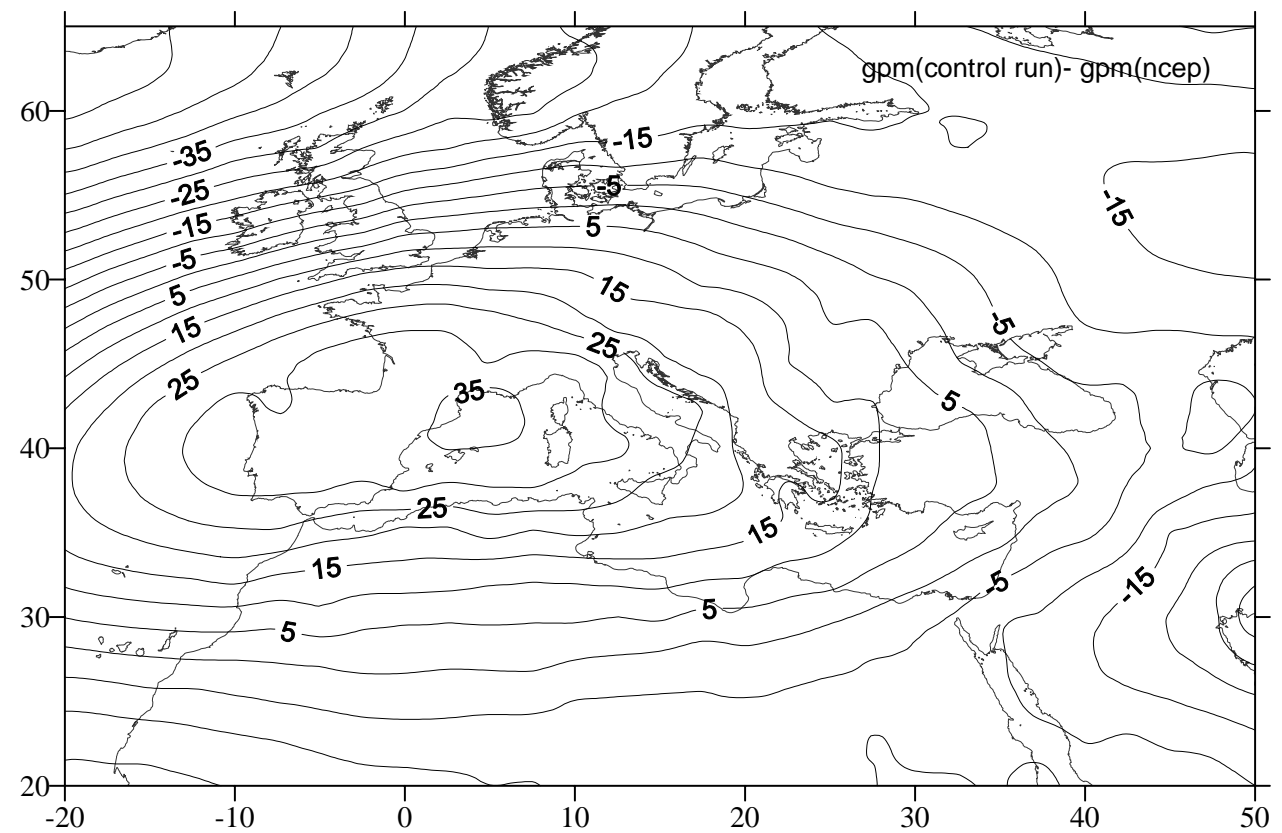

Figure 1. Spatial distribution of the mean winter biases between the HadAM3P control run and the NCEP datasets for $500 \mathrm{hPa}$ geopotential height.

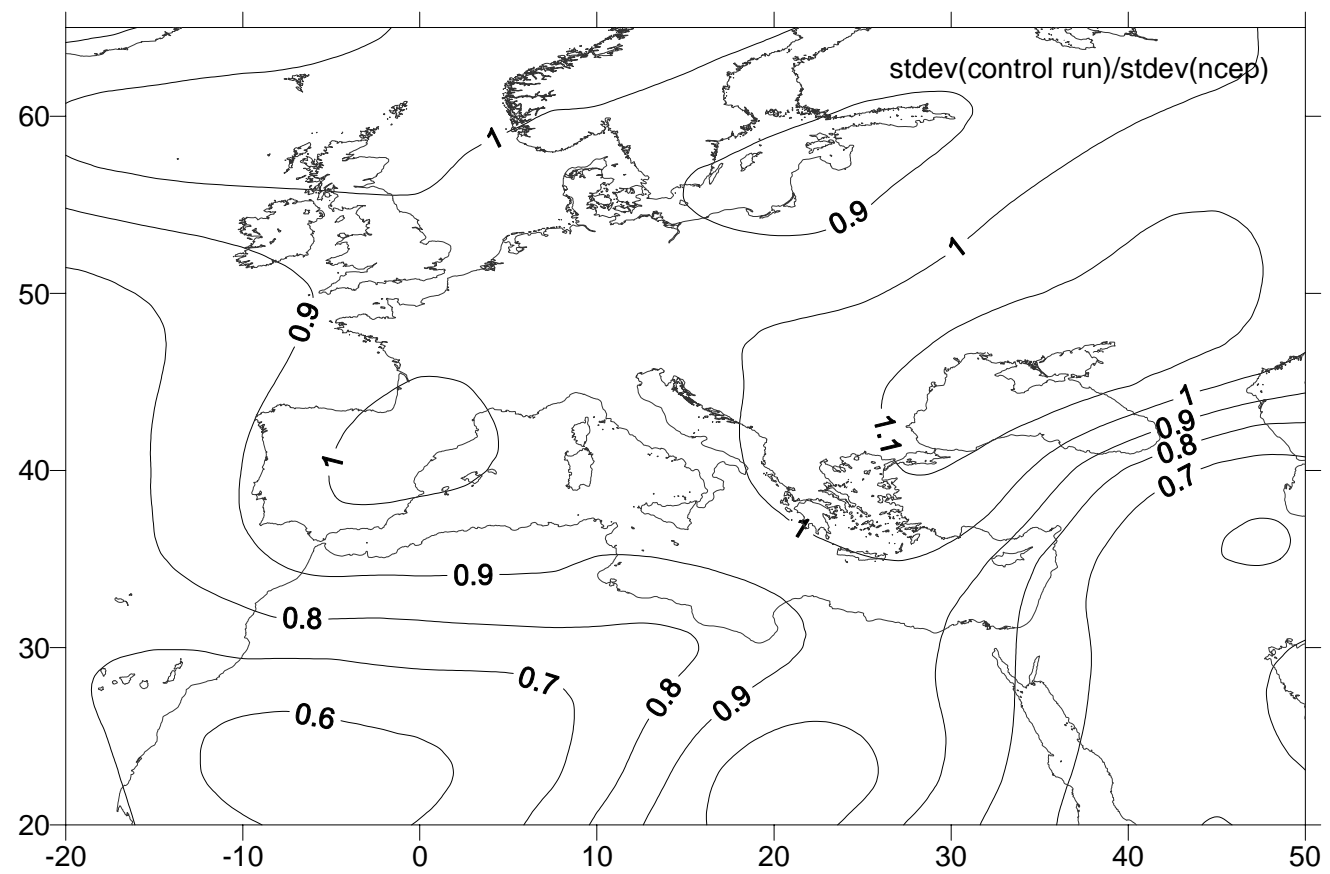

Figure 2. Spatial distribution of the standard deviations ratio of control run and NCEP geopotential heights datasets (control run/NCEP). 
More specifically, Hatzaki et al. [19] found for the present climate that the northern EMP pole is centered at $25^{\circ} \mathrm{W}, 52.5^{\circ} \mathrm{N}$ - which is not well depicted in the examined area of this study while the anti-pole over Eastern Mediterranean is centered at $22.5^{\circ} \mathrm{E}, 32.5^{\circ} \mathrm{N}$. For the future, the whole pattern is shifted northeasterly according to the A2a scenario, while the two poles have shifted to the southeast for the B2a scenario. The teleconnectivity for the A2a scenario is 0,65 while the corresponding value for the $\mathrm{B} 2 \mathrm{a}$ is 0,68 .

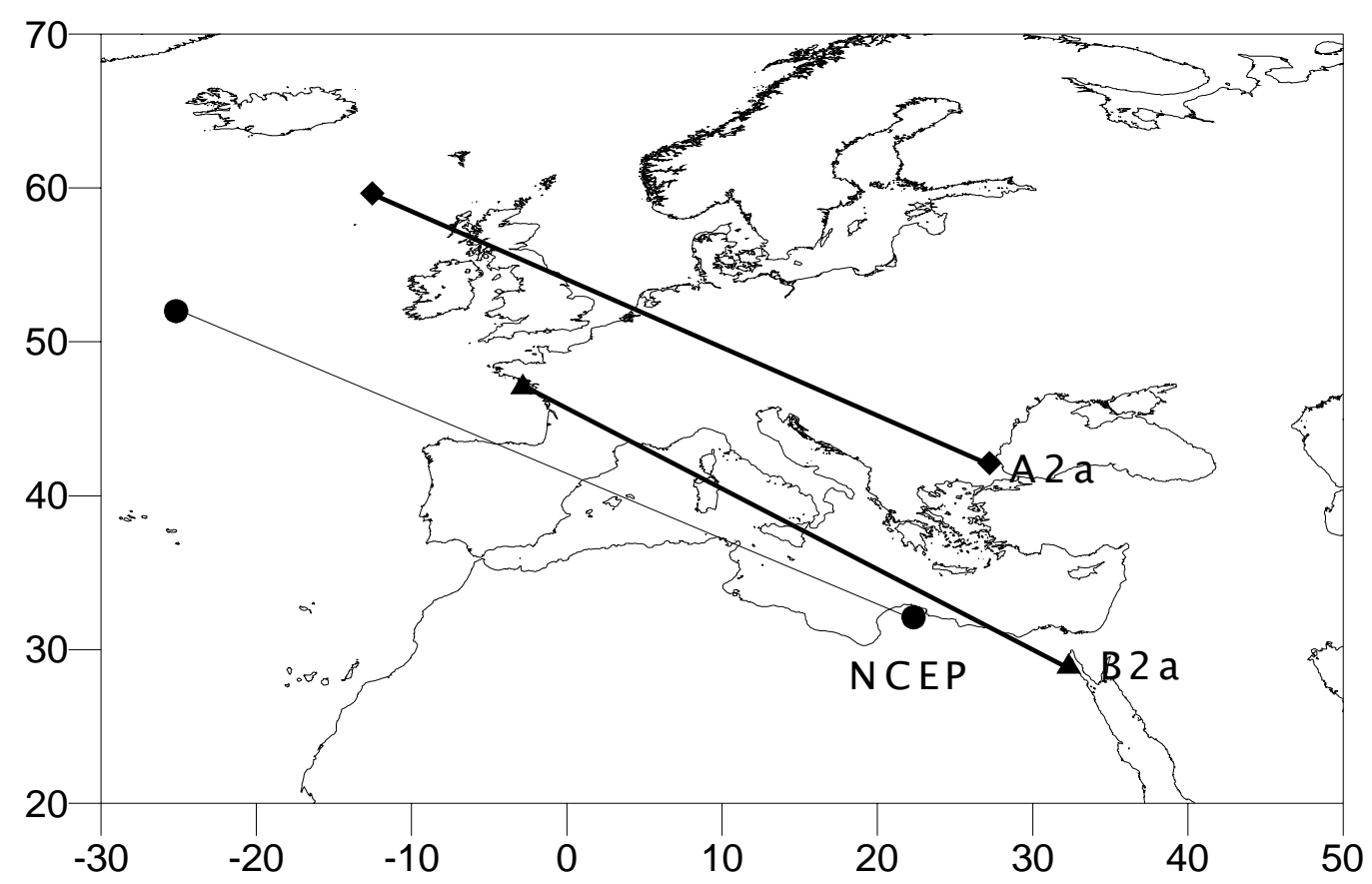

Figure 3. Negatively correlated pairs for NCEP data and A2a, B2a scenarios

Figure 4 shows the results of the PCA for the present climate and for the period 1961-1990, revealing the main configurations of winter atmospheric circulation at $500 \mathrm{hPa}$ over the European area. It can be seen that EMP is reflected in the first principal component (PC1), with a centre over the Northwestern Europe $\left(20^{\circ} \mathrm{W}, 50^{\circ} \mathrm{N}\right)$ and an opposite sign one over North Africa $\left(20^{\circ} \mathrm{E}, 20^{\circ} \mathrm{N}\right)$, explaining the $27,8 \%$ of the total variance. It should be noted that our results for a greater area and for the same period demonstrate a better verification and definition of the NW Europe-Eastern Mediterranean pattern (not shown). The third component seems to reflect the Eastern Atlantic-West Russia pattern (EAWR) [12], while the fourth component reveals the North Sea-Caspian pattern (NCP).

According to Figure 5, the EMP still exists for the scenario A2a, however, it now forms as the fourth component (PC4), explaining the $11.2 \%$ of the total variance. The locations of the two poles have also displaced both northward and eastward by almost $10^{\circ}$ relative to present climate results (Figure 4). This is more likely reflects the large increase of geopotential values that are expected for the A2 scenario over Eastern Mediterranean, reaching up to $100 \mathrm{gpm}$, as compared to the present climate [25]. The two poles are now positioned over the British Isles and Black sea, coinciding with the corresponding positions derived from the correlation analysis (Figure 3). It should be noted that the EMP pattern as displayed in this scenario resembles the EAWR pattern (PC3 of Figure 4).

For the scenario B2a (Figure 6), although the four PCs differ significantly compared to previous results (Figures 4 and 5), the EMP forms clearly as the second component (PC2), explaining the $20.6 \%$ of the total variance. A southeastward shift of the whole pattern relative to present climate is evident, resulting in relocation of the northern and southern pole over Western Europe and Red sea, respectively, in accordance with the correlation results shown in Figure 3. It is worth noting that the first component reveals seesaw behaviour between North Atlantic and Adriatic Sea that has not been found in the present climate and the A2a 
scenario. The other teleconnection patterns (EAWR and NCP) found in the present climate analysis (PC3 and PC4 of Figure 4) have not been represented by any of the first four components of the future climate.
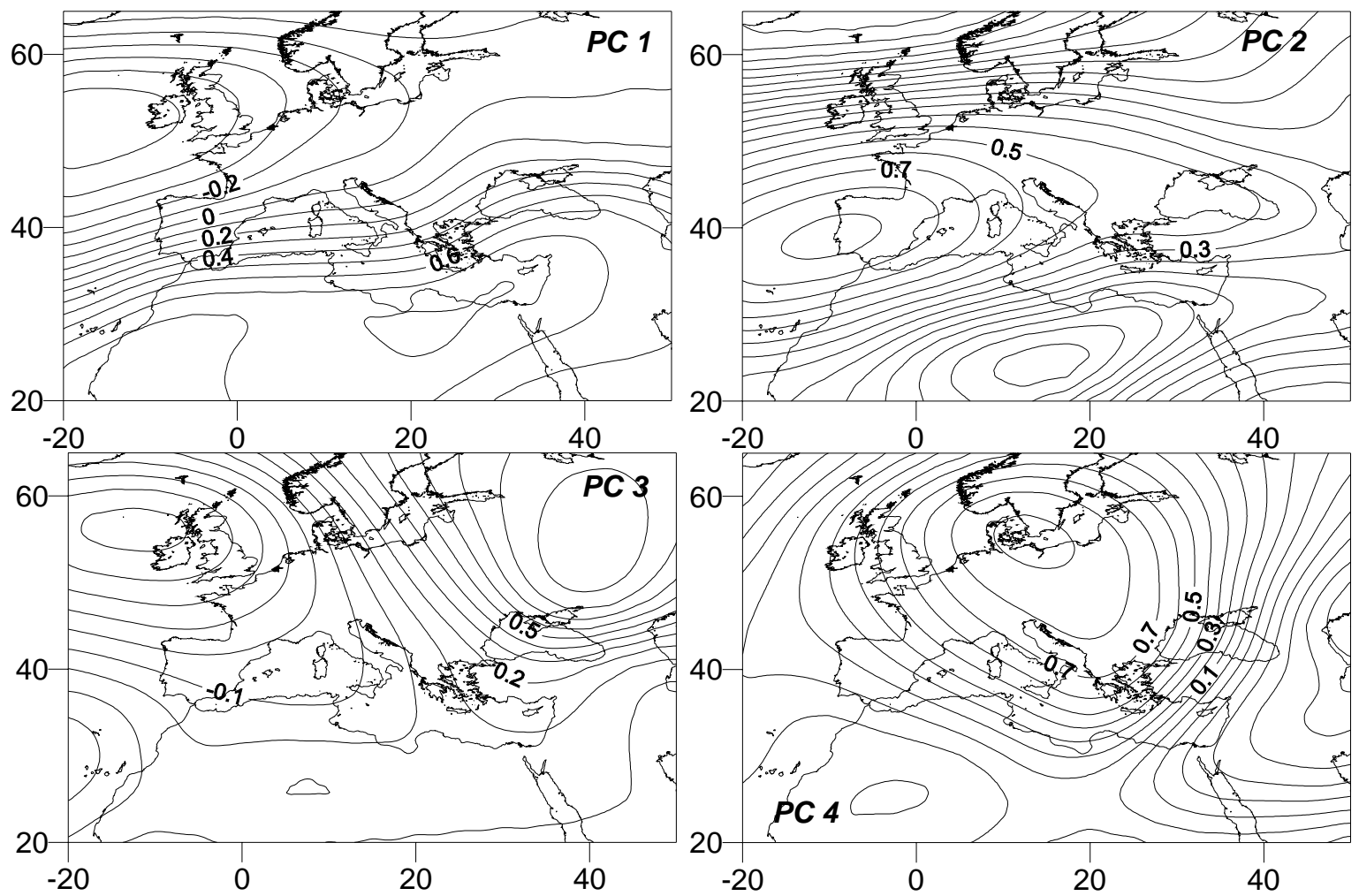

Figure 4. The four rotated principal components for the NCEP/NCAR data from $20^{\circ} \mathrm{W}$ to $50^{\circ} \mathrm{E}$ and $20^{\circ}$ to $65^{\circ} \mathrm{N}$ and for the $1961-1990$ period.
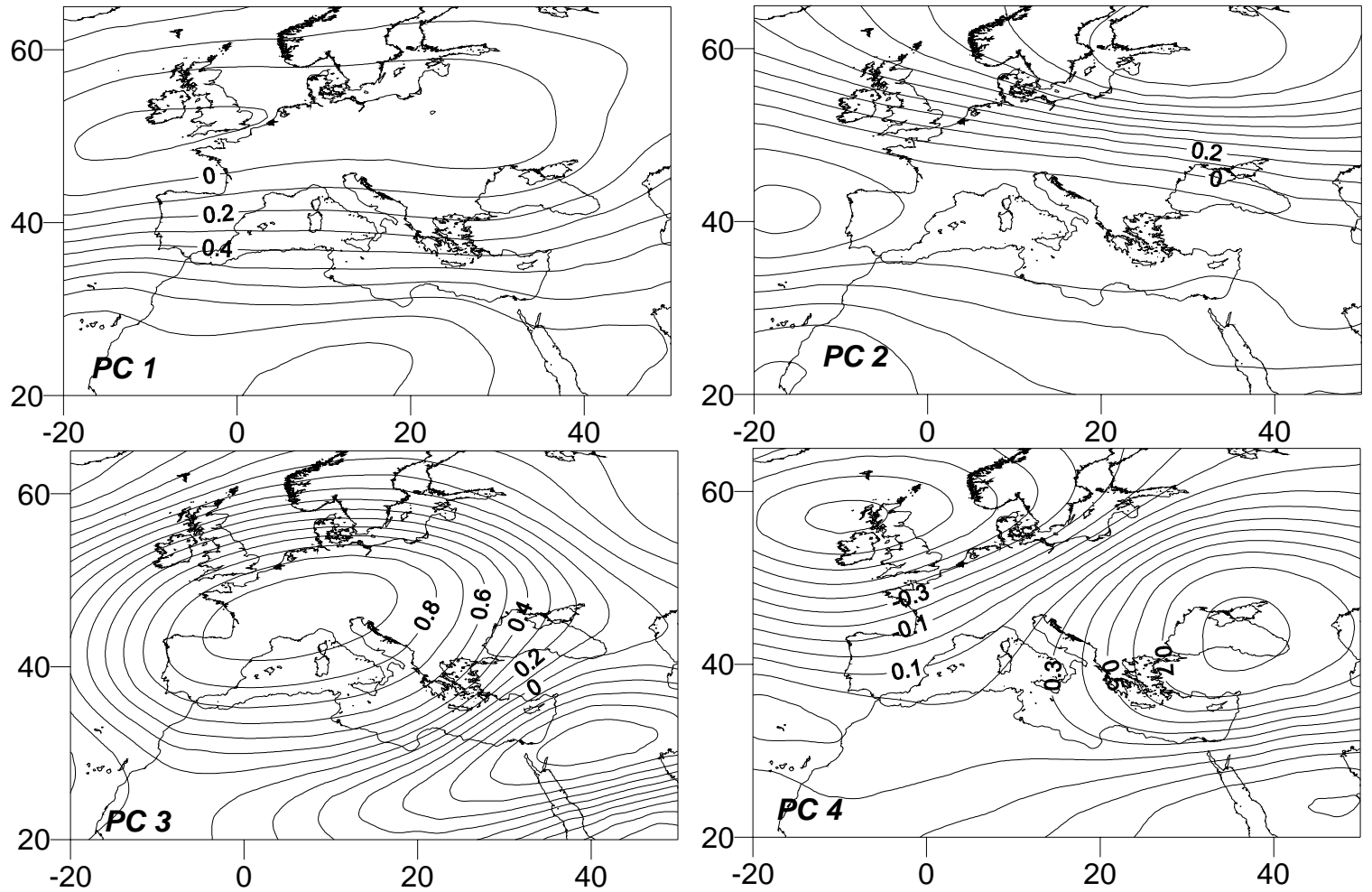

Figure 5. The four rotated principal components for the A2a scenario $20^{\circ} \mathrm{W}$ to $50^{\circ} \mathrm{E}$ and $20^{\circ}$ to $65^{\circ} \mathrm{N}$ and for the $2071-2100$ period. 

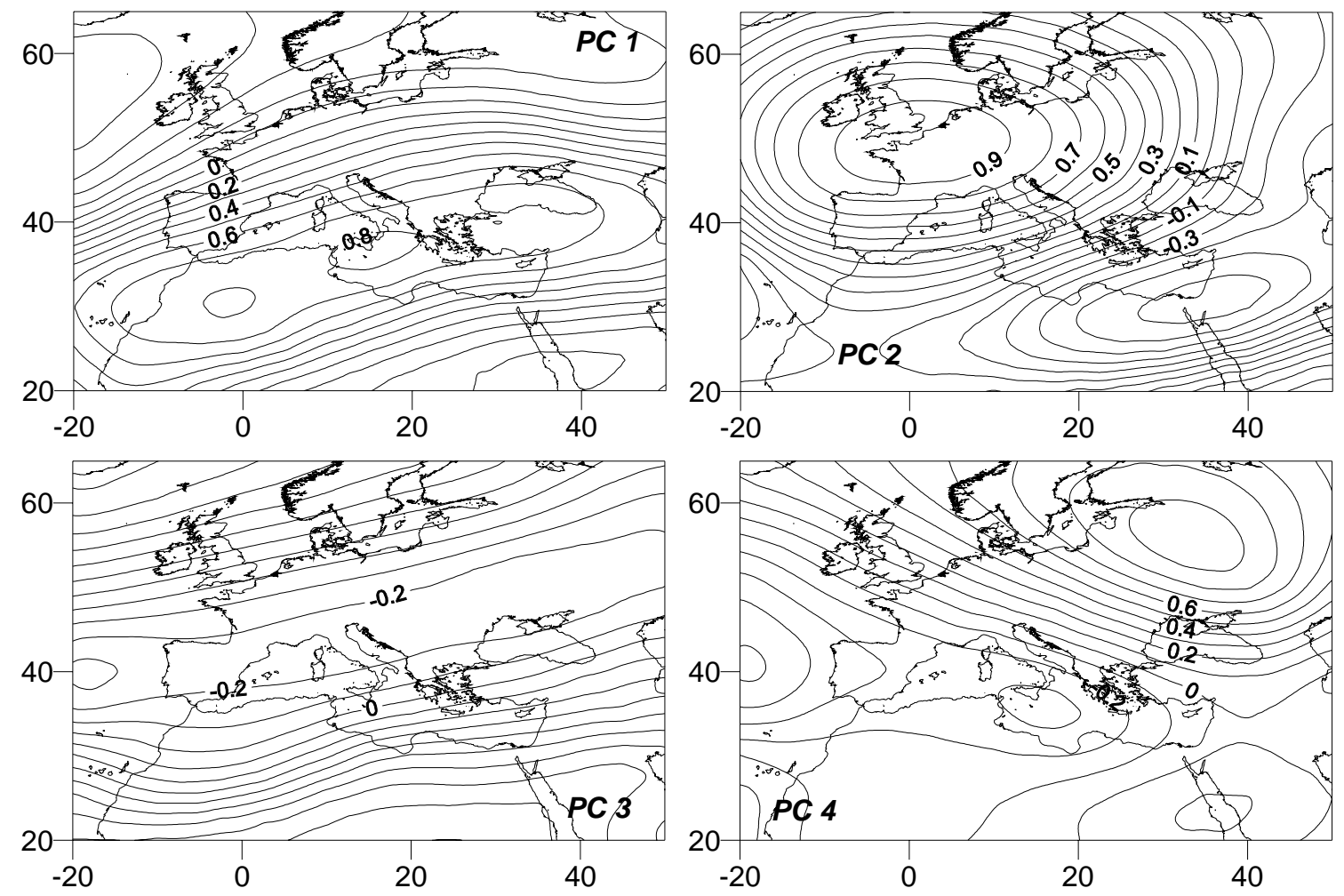

Figure 6. As in figure 5 but for the B2a scenario.

\section{CONCLUSIONS}

In this study an attempt is made to investigate the existence of the Eastern Mediterranean teleconnection pattern EMP, as a component of the low frequency atmospheric circulation at the upper levels in the future climate (2070-2100), employing the results of the GCM model HadAM3 based on two different IPCC scenarios regarding the emissions of the greenhouse gases. For this purpose, two different approaches have been used: principal component and correlation analysis.

The comparison of the $500 \mathrm{hPa}$ geopotential values of the model (control run) with the corresponding NCEP values for the present climate showed substantial underestimation over the region of the northern pole of the EMP (northwestern Europe) while no significant biases are evident over the region of the southern pole (Eastern Mediterranean). On the contrary, the variability of the two datasets is similar over the two regions.

The results of the correlation analysis suggest the existence of the EMP in the future for both scenarios with an eastward shift of the two poles relative to present climate. In the A2a scenario (that predicts global temperature increase by $3.3^{\circ} \mathrm{C}$ ) a northward shift is also evident. If the global temperature increase is lower (of $2.3^{\circ} \mathrm{C}$ in the B2a scenario), the two poles of the EMP are shifted southward. These results are verified by the principal components analysis, where the EMP forms as the fourth and the second principal component for A2a and B2a scenarios, respectively.

According to the results of the PCA, the EMP remains as a component of the upper level atmospheric circulation in the future while the other known teleconnection patterns (EAWR and NCP) have not been represented by any of the first four components of the future circulation. However, this finding could be considered with caution since it might depend on the extent of the examined area.

Similarly to other teleconnection patterns, in order to examine the intensity and temporal changes of EMP and to further investigate its relationship with the large scale circulation and the regional climate, a corresponding EMP index has been determined [19]. Taking into account that the definition of such a teleconnection index highly depends on the exact 
location of the two poles, the results of our study help to redefine the index for future scenarios and to further capture the intensity of pattern changes.

Since some characteristics of the future structure of EMP were marginally depicted in the examined area of this study, future research includes the investigation of the pattern in a more extended area. Furthermore, future changes of the pattern intensity and of its link with large scale circulation as well as implications on the future climate of Mediterranean will be examined.

ACKNOWLEDGEMENTS: This work was supported by the Commission of the European Union under the STARDEX (Statistical and Regional Dynamical Downscaling of Extremes for European Regions), contract (EVK2-CT-2001-00115) and funded by the State Scholarships Foundation of Greece through the scholarship of the Ph.D. student M. Hatzaki.

\section{REFERENCES}

1. Wallace J.M. and Gutzler D.S. (1981) Teleconnections in the geopotential height field during the Northern Hemisphere winter. Mon. Wea. Rev., 109, 784-811.

2. Blackmon M.L., Lee Y.H., Wallace J.M. and Hsu H.H. (1984) Time variation of 500mb height fluctuations with long, intermediate and short time scales as deduced from lag-correlation statistics, J. Atm. Sci., 41, 981-991.

3. Blackmon M.L., Lee Y.H. and Wallace J.M. (1984) Horizontal structure of 500mb height fluctuations with long, intermediate and short time scales, J. Atm. Sci., 41, 961-979.

4. Esbensen SK. 1984. A comparison of intermonthly and interannual teleconnections in the $700 \mathrm{mb}$ geopotential height field during the northern hemisphere winter. Mon. Wea. Rev., 112, 2016-2032.

5. Kutiel H. and Benaroch Y. (2002) North Sea-Caspian Pattern (NCP)-An upper level atmospheric teleconnection affecting the Eastern Mediterranean: Identification and definitions, Theor. Appl. Climatol., 71, 17-28.

6. Horel J.D. (1981) A rotated principal component analysis of the interannual variability of the northern hemisphere 500mb height field, Mon. Wea. Rev., 109, 2080-2092.

7. Hsu H.H. and Wallace J.M. (1985) Vertical structure of wintertime teleconnection patterns, J. Atm. Sci., 42, 1693-1710.

8. Barnston A.G. and Livezey R.E. (1987) Classification, seasonality and persistence of lowfrequency atmospheric circulation patterns, Mon. Wea. Rev., 115, 1083-1126.

9. Kushnir Y, Wallace JM. (1989) Low-frequency variability in the Northern Hemisphere winter: Geographical distribution, structure and time-scale dependence, J. Atm. Sci., 46, 3122-3142.

10. Hurrell JW, Kushnir Y, Ottersen G, Visbeck M. (2003) An overview of North Atlantic Oscillation: Climate significance and environmental impact, Eds. Geophysical Monograph Series, 134, 1-35.

11. Kutiel H. and Kay P.A. (1992) Recent variations in $700 \mathrm{hPa}$ geopotential heights in summer over Europe and the Middle East, and their influence on the meteorological factors. Theor. Appl. Climatol., 46, 99-108.

12. Krichak S.O. and Alpert P. (2005) Decadal trends in the East Atlantic-West Russia pattern and Mediterranean precipitation, Int J.Climatol., 25, 183-192.

13. Conte M., Giuffrida S. and Tedesco S. (1989) The Mediterranean Oscillation: impact on precipitation and hydrology in Italy, Conference on Climate and Water, vol.1, Academy of Finland 9/1989, pp. 121-137.

14. Maheras P., Xoplaki E., Davies T., Martin-Vide J., Bariendos M. and Alcoforado M. (1999) Warm and cold monthly anomalies across the Mediterranean basin and their relationship with circulation; 1860-1990. Int J Climatol, 19, 1697-1715.

15. Maheras P., Xoplaki E. and Kutiel H. (1999) Wet and dry monthly anomalies across the Mediterranean basin and their relationship with circulation 1860-1990. Theor. Appl. Climatol., 64, 189-199.

16. Kutiel $\mathrm{H}$, Maheras $\mathrm{P}$. (1998) Variations in the temperature regime across the Mediterranean during the last century and their relationship with circulation indices. Theor. Appl. Climatol., 61, 39-53.

17. Maheras P. and Kutiel $H$. (1999) Spatial and temporal variations in the temperature regime in the Mediterranean and their relationship with circulation during the last century, Int J Climatol, $19,745-764$. 
18. Hatzaki M., Flocas H.A., Maheras P. and Asimakopoulos D.N. (2004) On the study of teleconnection patterns affecting the Mediterranean region, 5th European Conference on Applied Climatology as part and partner of the 4th Annual Meeting of the European Meteorological Society, 26-30 September 2004, Nice, France.

19. Hatzaki M., Flocas H.A., Asimakopoulos D.N. and Maheras P. (2006) The Eastern Mediterranean Teleconnection Pattern: Identification and definition, Int. J. Climatol., (in press).

20. Hatzaki M., Flocas H., Giannakopoulos C., Maheras P. and Oikonomou C. (2005) Investigation of the impact of an upper troposphere teleconnection pattern on the Mediterranean climate, European Geosciences Union, 24-29 April 2005, Vienna, Austria.

21. Ulbrich U. and Christoph M. (1999) A shift of the NAO and increasing storm track activity over Europe due to anthropogenic greenhouse gas forcing, Climate Dyn., 15, 551-559.

22. Hu Z. and Wu Z. (2004) The intensification and shift of the annual North Atlantic Oscillation in a global warming scenario simulation, Tellus, 56A, 112-124.

23. Jones R., Murphy J., Hassell D., and Taylor R. (2001) Ensemble mean changes in a simulation of the European climate of 2071- 2100 using the new Hadley Centre regional modelling system HadAM3H/HadRM3H. Hadley Centre, Met Office, Bracknell, UK.

24. IPCC (2001) Climate Change 2001: the scientific basis. In: Houghton J.T. et al. (eds) Contribution of Working Group I to the Third Assessment Report of the Intergovernmental Panel on Climate Change. Cambridge University Press, Cambridge, UK, pp 881.

25. Tolika K. (2005) Estimated climatic changes in Greece during 21st century with the use of climatic models, PhD dissertation, University of Thessaloniki, Greece, pp 303. 